\title{
A IMPORTÂNCIA DO DEBATE AMBIENTAL EM COMUNIDADES RIBEIRINHAS DEGRADADAS NO MÉDIO RIO SOLIMÕES NO ESTADO DO AMAZONAS: UM DOS CAMINHOS PARA A SUSTENTABILIDADE
}

\author{
Ademar Vieira dos Santos ${ }^{1}$
}

Leidiano Lima Candido²

Xisto Tavares de Lima $^{3}$

RESUMO: Através desse estudo temos a finalidade de refletir em relação às atividades de extensão realizadas com a comunidade coariense sobre educação ambiental e meio ambiente. O tema do projeto, o local e a forma como as atividades foram desenvolvidas exigem de nossa parte como meio de estruturar e dar melhor compreensão e sustentação ao texto, a criação dos seguintes objetivos: refletir sobre o processo histórico do homem ribeirinho no contexto amazônico, a degradação ambiental e os novos paradigmas ambientais, entender a concepção de natureza e meio ambiente dos homens e das mulheres ribeirinhas em Coari, promover o envolvimento através de atividades de extensão dos professores/professoras e estudantes da UFAM/SEMED com o propósito de refletir coletivamente sobre a degradação ambiental que afeta as comunidades rurais. Como metodologia utilizou-se palestras, vídeos, desenhos e dramatizações. Como resultado foi possível observar que ao longo de cada atividade as crianças foram se tornando mais

\footnotetext{
${ }^{1}$ Formado em Pedagogia, Mestre em Educação Ambiental e Professor da Universidade Federal do Amazonas. santos.2012@r7.com

${ }^{2}$ Aluno de Curso de Biologia e Química da Universidade Federal do Amazonas. Santos.2012@r7.com

${ }^{3}$ Aluno do Curso de Matemática e Física da Universidade Federal do Amazonas. xistolima@yahoo.com.br
} 
receptivas, participativas e sensíveis em relação à educação ambiental e às questões ambientais. Este trabalho é relevante por possibilitar mudanças na concepção das crianças, dos professores e de toda a comunidade em geral sobre meio ambiente e natureza, educação ambiental e novas perspectivas de desenvolvimento na área rural onde eles vivem como sujeitos amazonenses.

Palavras-Chave: Educação Ambiental na Zona Rural

\section{INTRODUÇÃO}

Este artigo é resultado das reflexões realizadas a partir das experiências vivenciadas com professores/estudantes da Universidade Federal do Amazonas professores/professoras e crianças da Escola Municipal José Manoel de Souza da comunidade rural de Itapéua no Município de Coari/AM.

Para elaborar esse texto e refletir de forma mais contextualizada sobre educação ambiental e a degradação do meio ambiente na referida comunidade ribeirinha foram construídos os seguintes objetivos:

Refletir sobre o processo histórico do homem ribeirinho no contexto amazônico, a degradação ambiental e os novos paradigmas ambientais;

Entender a concepção de natureza e meio ambiente dos homens e das mulheres ribeirinhas na comunidade de Itapéua e em Coari de modo geral, e, por conseguinte buscar de maneira coletiva e dialogal estimular aqueles trabalhadores rurais através da educação ambiental, para que possam criar estratégias para superar os processos de degradação que lhes incomodam.

Promover o envolvimento por meio de atividades de extensão dos professores/professoras e estudantes da UFAM/SEMED com o propósito de refletir coletivamente e encontrar estratégias de superação dos problemas de degradação ambiental.

Isto a priori, por percebermos a necessidade que temos de entender os pressupostos do contexto histórico amazônico que de alguma forma influenciaram nas condições de degradação nas quais vivem os ribeirinhos naquela comunidade e em outras localidades do Amazonas. 
Por compreendermos também que qualquer estudo a ser realizado com a comunidade com o propósito de que eles possam superar a situação de degradação ambiental do local onde vivem, torna-se necessário que entendamos a concepção de natureza e meio ambiente que eles possuem como sujeitos protagonistas do meio onde vivem.

Isto nos potencializa perceber e planejar as atividades de educação ambiental que devem ser desenvolvidas na comunidade, de modo que aqueles ribeirinhos possam de alguma maneira refletir e pensar soluções concretas para os seus problemas, e, por conseguinte o desenvolvimento sustentável.

Essas atividades são relevantes por nos proporcionar convivência com os ribeirinhos, compreender suas realidades e de forma coletiva poder possibilitar momentos de reflexão sobre suas condições

ambientais. Também podem servir de referências para outros estudiosos, ou pesquisadores que queiram aventurar-se no estudo dessa que é uma das questões que mais incomoda as comunidades carentes.

\section{O CONTEXTO HISTÓRICO DO HOMEM NO GRANDE VALE AMAZÔNICO, O PROCESSO DE DEGRADAÇÃO E OS NOVOS PARADIGMAS AMBIENTAIS}

Ao longo dos séculos o homem amazônico viveu e se alimentou do extrativismo, do cultivo de diferentes plantas, das hortaliças regionais e dos peixes encontrados com muita abundância nos lagos e rios da região. "O homem coletando os bens da natureza vem de qualquer maneira assinalando a sua presença histórica na Amazônia" (BATISTA, 2007).

Porém nos dias atuais, o acelerado processo de degradação e esgotamento das potencialidades naturais, a prática de biopirataria, a cobiça nacional e internacional em relação às riquezas naturais amazônicas e os novos paradigmas ambientais põem em questão as formas históricas de relação de trabalho e de produção dos povos que vivem nesta região, até mesmo daqueles que residem às margens dos mais remotos rios e igarapés do interior do Estado do Amazonas.

De acordo com as novas diretrizes estabelecidas pelos órgãos ambientais, além das problemáticas ambientais e socioambientais que possuem, os agricultores precisam 
considerar as orientações dadas pelas leis ambientais de desmatamento para plantio de suas culturas e dos demais tipos de exploração das potencialidades naturais dos lugares onde vivem.

Percebe-se que a degradação, o desmatamento e a exploração desordenada das potencialidades amazônicas não são causados de certo modo pelos trabalhadores assentados, ou ribeirinhos, isto é, pessoas que exploram apenas para suas subsistências e de suas famílias.

Assim, entende-se que a devastação dos recursos naturais e da floresta amazônica pode estar sendo causada com muito mais intensidade por madeireiras, empresas de criação de gado, plantadoras de soja e até de pesca predatória descompromissadas com o desenvolvimento necessário ao povo que habita o Amazonas.

Porém, mesmo não sendo considerado causador do processo de desmatamento e devastação da Amazônia, o homem do meio rural precisa urgentemente incluir às suas atividades agrícolas de subsistência aos novos paradigmas ambientais. Desta forma entende-se que as pessoas que vivem do e no campo não podem continuar apenas reproduzindo as práticas agrícolas de seus ancestrais.

Com isso não se quer dizer que os saberes milenares dos homens e das mulheres amazonenses, construídos numa relação cotidiana íntima com o solo, num olhar atento aos astros, de forma dialogal com os seres sobrenaturais e com os outros homens, tenham que ser anulados ou tenham que ser considerados sobras de um passado superado. "A construção de uma racionalidade ambiental implica o resgate destas práticas tradicionais, como um princípio ético para a conservação de suas identidades culturais" (LEFF 2002, p.94-5).

Entendemos que esses conhecimentos continuam sendo de extrema importância na vida do agricultor, que eles podem ser reconstruídos e ressignificados frente às novas exigências paradigmáticas.

Diante disso, para que possam mudar as suas concepções sobre meio ambiente e também as suas práticas agrícolas, é fundamentalmente necessário que os amazonenses incorporem os conhecimentos, os saberes e as práticas que estão nos alicerces da civilização moderna para que assim, consigam refletir de forma concreta sobre as 
mudanças necessárias no processo de degradação da localidade e os demais contextos sociais.

Porém, é necessário entender que as relações econômicas e sociais instituídas pelas comunidades no interior do Amazonas resultam de um processo de relações que geraram uma espécie de unidade cultural. "O estudo das idéias das tradições, dos modos e linguagens, das técnicas, dos conhecimentos, da habitação, da alimentação, tudo demonstra essa admirável unidade social" (ARAUJO 2003, p. 143).

Partindo desses olhares, entende-se que qualquer projeto de mudança a ser ensinado ou colocado em prática que ignore esses valores e saberes significaria para os povos amazônicos a modificação de suas identidades, e, por conseguinte 0 distanciamento de um mundo imaginário e fantasmagórico, que de alguma forma ainda dá significado à vida de muitos caboclos amazonenses, interioranos, ribeirinhos. "O rio enchendo a vida do homem de motivos psicológicos, o rio imprimindo à sociedade rumos e tendências, criando tipos e características na vida regional" (TOCANTINS 1993, P.231).

Para alguns ribeirinhos, a forma geográfica dos igarapés em cujas margens residem e produzem as suas culturas, representa o desenho do corpo de uma grande serpente (cobra grande), que de acordo com a crença cabocla, pode um dia ter se transferido de um rio para o outro, fazendo da sua trajetória, com o peso do seu corpo, um igarapé. De acordo com os moradores, este lugar é abençoado, adubado naturalmente com os humos disseminados durante a enchente dos rios amazônicos, sobre as margens dos quais, plantando-se, tudo brotará. "Em cada civilização há sabedoria e superstições" (MORIN 2000, p. 27).

Diante disso, percebe-se que todas as atividades produtivas e sociais são resultantes não só da complexidade geográfica, mas também de todo um conjunto de crenças e saberes construídos pelos sujeitos protagonistas do meio rural amazônico.

As práticas produtivas, dependentes do meio ambiente e da estrutura social das diferentes culturas, que geraram formas de percepção e técnicas específicas para a apropriação social da natureza e da transformação do meio. Mas ao mesmo tempo, a capacidade simbólica do homem possibilitou a construção de relações abstratas entre os entes (LEFF 2002, p. 21). 
Porém, frente à nova realidade ambiental que se apresenta, esses saberes terão que ser questionados e repensados. Esse processo deve ser construído em parceria entre as instituições ambientais e os agricultores, com base na cultura da sociedade local, "o conhecimento, portanto, que é preciso tem de ser alcançado na relação dialógica" (SAVIANI 2003, p.52), de modo que os novos saberes necessários aos agricultores não se reduzam a uma mera transmissão dos conhecimentos sistematizados pelos órgãos ambientais.

Que essa construção possa se dar como um ato de criação e recriação coletivo de modo que os agricultores possam mudar as suas concepções de utilização do solo, de relações de produção, sem sofrerem desvalorização de suas identidades, e, assim, possam continuar produzindo, sem degradar o meio onde vivem, vivendo de forma sustentável nas suas próprias terras.

Essa situação apresenta-se aos professores, professoras, estudantes (pesquisadores) e às pessoas em geral que vivem no e do campo no Amazonas, como um novo processo de racionalização das práticas produtivas e das relações de apropriação da natureza. Isto requer dos educadores repensarem o currículo escolar das escolas dos assentamentos, das comunidades ribeirinhas e demais localidades da região, considerando-se que as mudanças que ora estão acontecendo influenciarão na cultural e em todo o processo de vida das pessoas que vivem nas grandes e pequenas comunidades no interior do Amazonas.

Essas diretrizes parecem colocar os professores e suas equipes de pesquisa diante de um grande desafio no seio da escola e fora dela, pois mesmo não sendo os únicos responsáveis por educar a sociedade em relação ao meio ambiente, eles são, de certo modo, nas escolas e na comunidade rural, as pessoas portadoras de um conjunto de saberes pedagógicos, filosóficos e metodológicos necessários à fomentação de uma educação e de um pensamento participativo e crítico do meio ambiente, voltado à construção do modelo de sociedade que se pretende formar, no meio rural, nas comunidades ribeirinhas e no Amazonas de modo geral, frente aos problemas ambientais enfrentados e os novos paradigmas. 
Em nosso entendimento, a escola faz parte de um contexto que engloba a sociedade, sua organização, sua estrutura, sua cultura e sua história. Desse modo, o projeto de ensino/aprendizagem está ligado a este contexto e ao modelo de cultura que orienta um modelo de homem/mulher que pretendemos formar para responder os desafios dessa sociedade (GHEDIN, et. al. 2004, .p. 42).

Isto em parte remete aos professores o compromisso por reestruturar filosoficamente os projetos, os conteúdos de Educação Ambiental que aprenderam para ensinar aos estudantes, aos assentados, e à comunidade em geral, possibilitando a todos a capacidade de debaterem e de construírem, de modo sustentável, as suas novas formas de pensar e de agir em relação ao cultivo sustentável da terra, aos problemas ambientais e socioambientais que lhes incomodam. Essa reestruturação não pode ignorar a história e a diversidade cultural desses povos, considerando-se que eles devem passar a assumir uma nova postura social em relação ao meio ambiente.

\section{A CONCEPÇÃO DE NATUREZA E MEIO AMBIENTE COMO MEIO DE REFLEXÇÃO NA INTERVENÇÃO DAS PRÁTICAS AMBIENTAIS AGRESSIVAS}

Para iniciar qualquer debate sobre meio ambiente e as condições de devastação e degradação do local onde vivem, as comunidades, necessariamente, precisam ter de certo modo formado uma concepção e um pensar próprio sobre natureza e o meio ambiente amazônico. "O pensamento é, mais que nunca, o capital mais precioso para o indivíduo na sociedade (MORIN 2002, p.18) Isto a priori deve ser pensado pelos próprios sujeitos que vivem nas comunidades num constante processo concreto de reflexão e interação com pesquisadores, professores e outros, essa relação não pode se dar de forma aleatória, pelo fato de ter que ser realizado de acordo com a realidade social, as potencialidades regionais, e, por conseguinte as novas perspectivas de desenvolvimento sustentável para a região. Isto de certa maneira:

Implica uma revolução do pensamento, uma mudança de mentalidade, uma transformação do conhecimento e das práticas educativas para construir um novo saber e uma nova racionalidade que orientem a construção de um mundo de sustentabilidade (LEFF 2003, p. 22) 


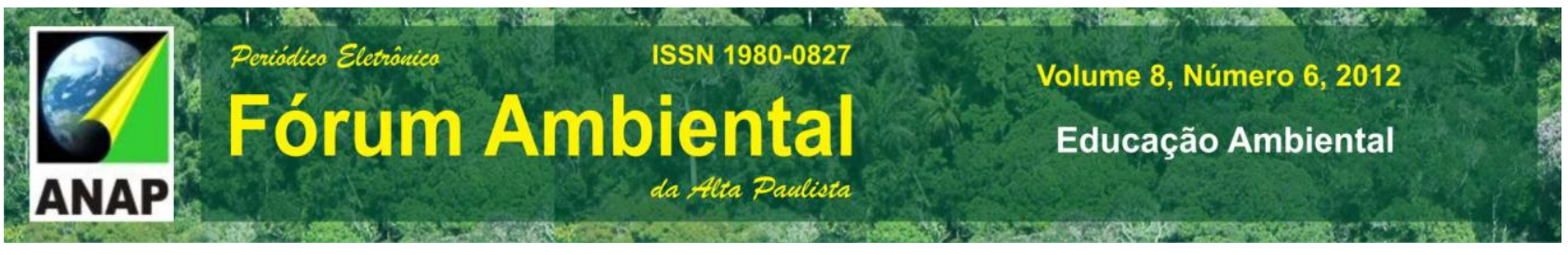

Diante dessa panorâmica entendemos que a natureza na Amazônia não pode continuar sendo contemplada como um santuário sacralizado, intocável. Diante disso, acredita-se que os homens e as mulheres amazonenses precisam perceber a natureza amazônica como um bem que deve ser preservado de forma equilibrada, o que significa dizer que podem explorar a natureza, porém preservando-a, de modo que as próximas gerações possam também explorar e viver dela de maneira sustentável.

Entende-se também que os trabalhadores, assentados ou comunitários que vivem às margens dos rios precisam se perceber como partícipes do meio onde vivem e não poderão polarizar ou compartimentabilizar ecologicamente o meio ambiente, excluir os seres humanos ignorando que o meio ambiente se constitui do meio geográfico, biológico ou ecológico, mas também do meio cósmico, e do social com suas instituições, suas problemáticas, suas culturas e seus valores (SANTOS 2005).

\section{A EXTENSÃO UNIVERSITÁRIA COMO FORMA DE PROMOVER O ESTUDO E A REFLEXÃO AMBIENTAL SOBRE A DEGRADAÇÃO E AS POSSIBILIDADES DE VISLUMBRAR O DESENVOLVIMENTO SUSTENTÁVEL EM COMUNIDADES RIBEIRINHAS}

Diante disso percebe-se a relevância dos projetos de extensão universitária nas comunidades ribeirinhas ou assentamentos rurais e a parceria dos professores das séries iniciais, de forma a estabelecerem a educação ambiental no currículo e nas diferentes disciplinas, evitando que a questão ambiental seja tratada apenas nos conteúdos ligados às áreas das ciências naturais e, dessa forma, possam sensibilizar as crianças das zonas rurais na construção de uma nova mentalidade sobre meio ambiente.

Uma visão da educação para o meio ambiente mais ampla deve envolver as pessoas da comunidade, os currículos escolares e a preparação dos professores em geral, não apenas aqueles que estão ligados às áreas das ciências biológicas ou da geografia (TRAVASSOS 2004, p.15).

Para isto entendemos que os professores e professoras das escolas rurais precisam desenvolver estratégias de ensino-aprendizagem que sensibilizem e motivem as 
crianças a adotarem novas práticas e hábitos em relação ao meio ambiente. "A educação ambiental tem que ser desenvolvida como uma "prática" para a qual todas as pessoas que lidam em uma escola precisam estar preparadas. Não basta que seja acrescentada como uma disciplina dentro da estrutura curricular" (TRAVASSOS 2004, p.12).

Nesse processo de construção é de fundamental importância que os professores e professoras criem momentos e atividades reflexivas através das qual os as crianças da zona rural demonstrem suas concepções sobre o meio ambiente, suas representações sociais em relação ao ambiente onde vivem, que elas tenham total liberdade de explicitar seus sonhos e até mesmo suas frustrações diante da falta de algum mantimento, ou outra situação qualquer que esteja Ihes causando desconforto no meio familiar ou na escola onde estudam.

No nosso ponto de vista, a educação para o meio ambiente é, portanto, um assunto que deve ser tratado de maneira integrada, englobando a prática pedagógica e a representação social dos sujeitos envolvidos, colocando as pessoas como participantes de um mesmo processo, na tentativa de solucionar os problemas ambientais. (TRAVASSOS 2004, p.12).

Entende-se que a educação ambiental não deve simplesmente ser um conteúdo ensinado e apreendido em sala de aula com as crianças. Percebe-se que existe um grande potencial de recursos didáticos, pedagógicos que podem ser utilizados com o propósito de fazer com que os aprendizes vivenciem a educação ambiental de forma lúdica, isto é, através de situações que lhes emocionem, e, por conseguinte como dizia o Educador Paulo Freire Ihes toque a alma.

As histórias em quadrinhos combinam imagem e texto escrito, constituindo um código específico, procurando a participação ativa do leitor por via emocional, anedótica, assistemática, concreta em muitos casos, as historietas assumem função apelativa, especialmente quando expressam instruções para melhorar uma atitude, adquirir um hábito, alertar para perigos eminentes e outros (RUSCHEINSKY 2002 p. 161).

Entendemos que através desses recursos os aprendizes podem expressar melhor seus sentimentos, e, por seguinte se tornarem mais curiosos e interessados pelo estudo 
da questão ambiental. Tais atividades podem de alguma forma motivar até mesmo as pessoas adultas nos mais diferentes graus de ensino, dentro e fora dos muros da escola.

- A Educação Ambiental deverá enriquecer a formação do aluno, propiciando o conhecimento de princípios básicos e o desenvolvimento de uma consciência ambiental.

- despertar a sensibilidade para observar e perceber a importância da natureza (solo, flora, fauna, ar) para a qualidade de vida.

- demonstrar a importância do exercício contínuo de cidadania, visando a valorização do entorno natural e cultural;

- desenvolver a capacidade para o reconhecimento, valorização, respeito e preservação do meio ambiente, para impedir a descaracterização das peculiaridades locais e regionais (FARIA 2001, p.82).

A complexidade que envolve essa questão exige por parte dos educadores nas atividades de extensão, e de outras pessoas envolvidas com esse assunto maior esforço e reflexão no sentido de buscar de maneira concreta conhecimentos ambientais mais abrangentes e nas diferentes fontes e formas de linguagem e representações da leitura do mundo que não estão restritos apenas às disciplinas escolares ou em alguns poucos livros e revistas.

Acreditamos que os conhecimentos surgidos dessa interação devem potencializar nos ribeirinhos a capacidade de refletir sobre novas formas de proteger o solo, maneiras de preservar da poluição os mananciais próximos das comunidades, como também de descobrirem novas maneiras de lidar com os tipos de culturas que há muito tempo já costumam plantar nas suas lavouras, e ao mesmo tempo sejam capazes de descobrir outros tipos cultiváveis na região que possam melhorar a alimentação e a vida de todos na localidade.

Portanto, entendemos que as atividades formais e informais realizadas por professores e pesquisadores de forma comprometida através das atividades de extensão nas comunidades ribeirinhas podem em muito contribuir no processo de informação, promovendo conscientização nas pessoas que residem nos mais remotos lugares desse grande Estado, de modo que se possa promover nas novas gerações uma outra reflexão sobre desenvolvimento sustentável e qualidade de vida dos povos que vivem no campo e do campo. 
Esperamos que os ribeirinhos possam lutar de maneira engajada, tendo clareza do tipo de desenvolvimento que querem para eles e para os seus filhos.

"É preciso, também, perceber que o desenvolvimento deveria ter como finalidade: viver com compreensão, solidariedade e compaixão. Viver melhor, sem ser explorado, insultado ou desprezado" (MORIN 2003, p.105).

Por entendermos também que o desenvolvimento sustentável no Amazonas tem necessariamente que se dar a partir dos movimentos sociais, da luta política dos próprios amazônidas, não será mais possível conceber as propostas ou parcerias desenvolvimentistas oferecidas por personalidades internacionais ou até nacionais. De certo modo elas são agressivas, pois acabam se transformando em práticas espoliativas, através das quais os colonizadores ou exploradores passam a levar as nossas potencialidades de maneira indiscriminada. Dessa forma entendemos que nossa postura enquanto estudantes, professores, pesquisadores e agricultores não pode ser de passividade diante de tais situações. Frente a isso, as atividades educativas devem de alguma maneira sensibilizar os ribeirinhos á práticas ambientais criativas sustentáveis, ao mesmo tempo resistentes e radicais a promessas de projetos de meio ambiente que não atendam as suas demandas.

O comportamento $\mathrm{e}$ as práticas políticas dos homens e das mulheres amazonenses deve de alguma maneira fazer erradicar a concepção e a postura eurocêntrica existente em relação aos povos que aqui vivem, de que não são capazes de pensar, desenvolver e criar condições sustentáveis de vida e que todos os projetos têm obrigatoriamente de ser elaborados por mentes iluminadas que muitas vezes vivem fora do contexto regional.

Com isto não queremos dizer que vamos viver de forma isolada no mundo globalizado. Precisamos ser potencialmente inteligentes para saber utilizar as idéias globais na construção dos projetos locais, sem ter que ser necessariamente e exclusivamente conduzidos pelos outros, sem ter que perder nossa identidade e liberdade. Entendemos que diante de tantas perdas históricas, mesmo de forma tardia se faz necessário mudar nossa postura de posse em relação à Amazônia. 


\section{CONSIDERAÇÕES FINAIS}

Promover debates sobre degradação e preservação ambiental em comunidades ribeirinhas no Estado do Amazonas parece ser um grande desafio das pessoas que se aventuram a tal atividade.

Em primeiro lugar, os professores/professoras e estudantes universitários precisam, além de um projeto de extensão com objetivos bem definidos, estar individual e coletivamente conscientes do que realmente querem para o Amazonas, para os ribeirinhos.

Em segundo lugar, as atividades realizadas devem suficientemente sensibilizar as crianças ou demais sujeitos, de modo que eles se sintam participes do debate, visto que para todos eles, este momento representa um novo paradigma, pois nunca foram convocados para refletir e tomar decisões em relação aos seus próprios problemas ambientais.

Isto de certa maneira nos potencializa perceber que as atividades de extensão devem ser capazes de possibilitar aos ribeirinhos romperem com a centenária cultura do silêncio visto que pelo tipo de colonização que tivemos, os nativos ou ribeirinhos apenas possuíam o direito de concordar com todas as decisões políticas, econômicas e culturais que os colonizadores, os seringalistas, latifundiários e os coronéis de barranco decidiam tomar em relação às suas vidas no Amazonas. Diante disso, entendemos que juntamente com os ribeirinhos, precisamos refletir sobre novos cenários socioambientais nas comunidades, um novo tipo de comportamento político, e uma nova cultura.

Para isto entende-se que o trabalho dos professores/professoras nas escolas ribeirinhas deve ser realizado dentro de uma perspectiva interdisciplinar, fazendo com que eles possam superar as suas visões fragmentadas entre as disciplinas e os diferentes conhecimentos.

Dessa forma estarão sensibilizando as crianças e demais pessoas da comunidade a mudar seus antigos hábitos ambientais. Desse modo poderão também superar suas individualidades de maneira que possam trabalhar em prol da coletividade e, numa 
constante forma dialogal, possam também enfrentar a situação de degradação ambiental do lugar onde vivem.

\section{REFERÊNCIAS}

ARAUJO, André Vidal. Introdução a Sociologia da Amazônia. Manaus: Editora Valer 2003. p 606.

BATISTA, Djalma. O complexo da Amazônia. Análise do processo de desenvolvimento. Manaus: Editora Valer 2007. P 607.

FARIA Ivanir Ferreira. Turismo Sustentabilidade e Novas Territorialidades. Coleção Geografia e Turismo. Manaus: Edua 2001.

LEFF, Enrique. Epistemologia Ambiental. São Paulo: Cortez, 2002. 239p.

Saber Ambiental. Petrópolis: Vozes, 2002494 p.

GHEDIN et. al. Manual de Didática I. Manaus: Universidade do Estado do Amazonas: 2003. $80 \mathrm{p}$.

MORIN, Edgar. Saberes Globais e Saberes Locais. O olhar transdisciplinar. Rio de Janeiro: Garamond 2002. 73 p.

,Repensar a Reforma. Reformar o Pensamento. A Cabeça bem Feita. Lisboa: Instituto Piaget 2002. 137p.

Educar na Era Planetária. O pensamento complexo como método de aprendizagem pelo erro e incerteza. São Paulo: Cortez 2003. 111p.

SANTOS. Ademar. A questão da Educação Ambiental na Formação do Professor: um enfoque epistemológico a partir do projeto Proformar na cidade de Manaus/AM Dissertação de mestrado 2007. 100 p.

RUSCHEINSKY, Aloísio. Educação Ambiental. Abordagens Múltiplas. São Paulo: Artmed 2002. $183 \mathrm{p}$. 
TOCANSTINS, Leandro. O Rio comanda a vida: Uma interpretação da Amazônia. Rio de Janeiro: José Olympio, 1983. 284p.

TRAVASSOS, Edson Gomes. A prática da Educação Ambiental. Porto Alegre: Editora Mediação 2004. 77p. 